Article

\title{
Building Sustainable Contextual Ambidexterity through Routines: A Case Study from Information Technology Firms
}

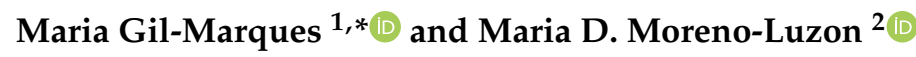 \\ 1 Department of Economics, Business Management and Marketing, Universidad Católica de Valencia San \\ Vicente Mártir, 46003 Valencia, Spain \\ 2 Department of Business Management, University of Valencia, 46022 Valencia, Spain; maria.moreno@uv.es \\ * Correspondence: maria.gil@ucv.es
}

Received: 30 October 2020; Accepted: 16 December 2020; Published: 19 December 2020

check for updates

\begin{abstract}
The purpose of this paper is to explain the role that routines play in achieving sustainable organisational ambidexterity in information technology (IT) firms. Our exploratory analysis of four case studies reveals the key importance of routines in setting the context for sustainable ambidexterity. Companies build up contextual ambidexterity through routines derived from normalization of processes, normalization of skills, and normalization of results. The findings of the study show that routines support IT professionals to decide whether to exploit or explore in each particular case. Firstly, the enabling character of explicit routines as a result of the normalisation of work processes and the freedom that IT professionals have when implementing them, allows IT professionals to balance exploitation and exploration. Secondly, companies build up contextual ambidexterity through normalisation of skills. Hence, IT professionals develop embedded implicit routines as a result of training. Thirdly, the findings of the study reveal how routines are settled through the normalisation of results that orientates performance towards satisfying customer demands, as well as supporting professionals in their efforts to balance between exploitation and exploration which is necessary to achieve sustainable ambidexterity in IT firms.
\end{abstract}

Keywords: ambidexterity; exploration; exploitation; routines; capabilities; IT firms

\section{Introduction}

Ambidexterity, understood as the ability to perform exploitative and exploratory activities with equal skills [1-3] has offered a solution to the classic dilemma of efficiency versus flexibility that has inspired numerous academics and managers, and remains relevant for companies who wish to compete in dynamic environments [4]. Dynamic capabilities are defined as "the firm's ability to integrate, build, and reconfigure internal and external competences to address rapidly changing environments" [5] (p. 1395). Organisational ambidexterity is seen as a dynamic organisational capability in itself [6,7]. Following Teece's definition, ambidexterity makes it possible to reconfigure exploitation and exploration competences to adapt to the requirements of the environment. As it is a dynamic capability, ambidexterity should be based on the knowledge and skills of professionals [8]. Furthermore, as Teece et al. [8], Eisenhardt and Martin [9], and Kogut and Kulatilaka [10] have stressed, an organisation's capability to compete in the long term relies on integrating and enhancing current competences, while developing new ones. Given that exploitation and exploration are capabilities, we can define ambidexterity as the dynamic capability to use exploitation and exploration to efficiently adapt to external requirements.

Ambidexterity is a critical dynamic capability for long-term company survival and growth [11]. Organisational ambidexterity is positively and significantly related to organisation performance in 
an uncertain and complex environment [12]. Organisations try to achieve ambidexterity to grow, to sustain, and to be competitive [13] as well as to adapt to environmental changes [14].

Gibson and Birkinshaw [15] found a positive relationship between contextual ambidexterity and performance. Contextual ambidexterity is rooted in a context which favours the balance between exploitation and exploration so that the adaptation of the organisation is facilitated, but research on how to achieve such ambidexterity is still limited [11-13].

Although the literature shows that ambidexterity can be developed through a favorable context, research does not illustrate under what conditions routines can create this context. This study attends to address this gap, analysing the antecedents of contextual ambidexterity and focusing on the role of routines to examine the extent to which they may serve as an antecedent that enables firms to develop a context for ambidexterity.

Our main objective is to explore this question suggesting an original perspective of routines by differentiating between coercive and enabling routines, bearing in mind how routines are developed by automatic coordination mechanisms and flexibly implemented by individual people in order to adapt to change.

The aim of this paper is to answer the following main research question: How can routines support the development of contextual sustainable ambidexterity? Specific questions derived from the main research question include the following: By what means are these routines produced and maintained? What is the role of normalisation of work processes, skills, and results to generate these routines in the company? How can routines support the development of exploitation and exploration organisational capabilities?

To answer these questions, a multiple exploratory case study was conducted at four IT consultancy service companies. Overall, in this paper, we aim at addressing this gap to deepen our understanding of the complexity of routines and their impact on adaptation and change, by exploring the interactions among operational routines and a dynamic capability, specifically ambidexterity, as well as taking an in-depth look into the connections among them.

The key to explain how operational routines can facilitate ambidexterity relies on the fact that routines can be enabling and flexible, and not necessarily connected with stability and rigidity (Adler \& Borys, 1996). To grasp the meaning of routines, we borrow insights from Mintzbergs' theory about coordination mechanisms that generate routines, namely, normalization of processes, skills, and results [16]. We also take on board Feldman and Pentland [17], who explained the flexible part of routines that is connected with the way they are implemented; as well as Adler and Borys' [18] differentiation between coercive and enabling routines, with the latter more flexible than the former one.

Following the above mentioned, the intended contribution of this paper is two-fold. First, we suggest a framework to provide a proper understanding of the complexity of the routines. Second, we shed light on the link between operational routines and ambidexterity, which is a challenging dynamic capability needed to sustain and to compete in dynamic environments $[15,19,20]$. Both contributions have practical and theoretical implications.

This study enriches the literature on ambidexterity by explaining how operational routines can contribute to the balance between exploitation and exploration, which is necessary to achieve sustainable ambidexterity in IT firms. Our findings can help managers to crystallize the knowledge of routines, and how to use them in the management of sustainable contextual ambidexterity. Specifically, managers could appreciate the implementation of enabling and flexible routines, which can be developed through the use of normalization of work processes. Moreover, the normalization of skills and the normalization of results create a context supporting professionals to decide on an adequate balance between exploration and exploitation. 


\section{Literature Review: The Role of Routines in Generating Sustainable Contextual Ambidexterity}

\subsection{Ambidexterity}

March [21] was a pioneer in underlining the need for a balance between exploitation and exploration, although he did not mention the term ambidexterity. However, he highlighted the important exploration/exploitation tradeoff and the threat to companies' long-term competitiveness if they created an imbalance between these two ways of acting and learning. The risks of this imbalance have been underlined by subsequent studies [22,23].

Ambidexterity has been featured extensively in the most prestigious management journals. Such is this topic's importance that it has been cited by some authors as an emerging paradigm in organisational theory [24-26], and as an important and promising research stream [2,27]. Lavie et al. [28], O'Reilly and Tushman [2], and Raisch and Birkinshaw [24] discussed the state of the art. Managing for ambidexterity is a task of dynamic rather than static alignment [25]. In fact, some authors have stated that the dynamic capability framework was the most appropriate one to explain this phenomenon $[2,27,29,30]$. "Dynamic capabilities are high level competences that determine the firm's ability to integrate, build, and reconfigure internal and external resources and competences to address, and possibly shape, rapidly changing business environments" [5] (p. 1395). Companies need to combine exploration and exploitation, obtaining benefits from both, and therefore adapt to environmental changes to pursue a sustainable ambidextrous capability [11,14].

Research on this topic advocates that organisational ambidexterity can arise from structure (structural ambidexterity) or behaviour (contextual ambidexterity) $[2,15,24,25]$. Structural ambidexterity advocates the creation of organisational units specifically focused on alignment and continuity, and others focused on carrying out rapid environmental changes. Scholars have echoed this approach in proposals for structural ambidexterity to resolve the exploitation/exploration dilemma through top management coordination and the separation of exploitative and exploratory units with different processes, structures, and culture $[2,7,27]$.

Gibson and Birkinshaw [15] suggested a different approach to ambidexterity creating a context that allows individuals to divide their time between exploration and exploitation. Contextual ambidexterity is a capability embedded in organisational behaviour. Individuals are encouraged to use their own judgment in combining explorative and exploitative activities [15]. Adler et al. [4] described how Toyota production systems created a context where employees performed routine tasks but also new tasks. This context resulted from designing and establishing processes and systems that encouraged employees to allocate time to different activities, i.e., either by continuing previous activities or changing to meet environmental demands. Previous researches have highlighted several advantages of contextual ambidexterity over structural ambidexterity derived from the fact that adaptation of the organisation was facilitated, but research on how to achieve such ambidexterity is still limited $[19,20]$.

\subsection{Routines}

Routines are part of an organisation's memory and are a fundamental means by which organisations efficiently meet their goals [31]. Organisational routines are defined as "repetitive, recognisable patterns of interdependent actions, carried out by multiple actors" [17] (p. 95). Routines as patterns of interdependent actions carried out by multiple actors $[17,32]$ are, from our perspective, the result of different types of standardisation. There is a literature review of the concept in Becker [33].

Routines have traditionally been associated with a lack of flexibility. They are a source of regularity and continuity, which is a defining trait of bureaucracies. Routines have also been associated with standardisation, specialization, and repetition of non-intellectual tasks [34], as well as tasks that can be performed automatically [35]. Routines exploit accumulated knowledge, and thus drive organisations towards efficiency [4]. However, routines are not necessarily connected to inflexibility and inertia, and can also be a source of adaptation and change. This is the approach we take in this paper, and we pay special attention to the three studies presented below. 
To begin, we investigate the well-known approach of Mintzberg on coordinating mechanisms [16], who clearly differentiated between distinct types of standardisation. The purpose of routines is to formalize actions reducing undesired variation, and to anticipate actions allowing desired variation [16]. According to Mintzberg's model, there are some coordination mechanisms that are automatic, and not personal, such as standardisation of processes, standardisation of results, and standardisation of skills, all of them creating different kinds of routines in the organisation [16].

First, standardisation of work processes ensures coordination by specifying the work to be done so that no decisions have to be taken later, because the contents of the work are planned and specified [36]. The behaviour formalization implies rules or guidelines are developed stipulating the way decisions and actions are to be carried out [37]. Second, standardisation of skills happens when the kind of training required to perform the work is specified for a specific work [36]. Usually, the worker is trained before joining the organisation, but job-related skills and knowledge can be taught by the company [38]. When standardisation of skills is used as coordinating mechanisms, decisions are based on expertise, and peers know what to expect from each other [36]. Thirdly, standardisation of results implies defining goals and controlling performance, monitoring the degree to which goals have been achieved [36-38]. Standardisation of results can be the source of different kinds of routines in the organization, enabling employees to better master their tasks and functions, and improving the effectiveness of the organisation [36-38].

Moreover, we look at the work of Feldman and Pentland [17] who differentiated between the structural or ostensive (stable) aspects of routines and the practical or performative (variable) side, bringing routines to life through specific actions, by particular people, at precise times and places. Therefore, the practical side endows every organisational routine with the capability to produce change. Feldman and Pentland [17] (p. 107) commented on the interplay between the structural and practical sides of routines, "The relationship between ostensive and performative aspects of routines creates an on-going opportunity for variation, selection, and retention of new practices and patterns of action within routines and allows routines to generate a wide range of outcomes, from apparent stability to considerable change".

Finally, a relevant perspective taken into account in this paper is the differentiation introduced by Adler and Borys [18] between two types of routines, i.e., enabling and coercive. Enabling processes are designed with the participation and cooperation of workers based on trust. These rules do not alienate employees, but rather coordinate and motivate them by supporting people when resolving problems and facilitating innovation and commitment. This is true of many quality management programs, in which employees cooperate to design procedures that regulate their own work [39,40].

By contrast, coercive routines are dictated by management to avoid mistakes and to sanction deviations. Therefore, these routines force subordinates to follow them, which can lead to frustration and alienation [41]. Coercive rules are difficult to change because any possible modification is viewed with trepidation by those in power, and they are established in contexts of insecurity for workers, limited opportunity for participation, and rigidity $[18,42]$. We present the main features of enabling and coercive systems in Table 1.

Table 1. Features of enabling and coercive systems. Adapted from Adler and Borys [18].

\begin{tabular}{cc}
\hline Enabling Systems & Coercive Systems \\
reinforce commitment & $\begin{array}{c}\text { Support management and supervisors, } \\
\text { and sanction deviations }\end{array}$ \\
Support employees to achieve effectiveness and & Dictated by management \\
Created and designed with employee participation & of learning \\
Problems are opportunities, and mistakes are sources & Problems constrain people and mistakes are avoided \\
They foster differences and promote trust & They are suspicious of differences \\
Flexible, adaptable, and changing & Rigid, not adaptable or changeable \\
\hline
\end{tabular}




\subsection{Links between Routines and Ambidexterity as a Dynamic Capability}

The close connection between routines and capabilities has been recognised in the literature. According to O'Reilly and Tushman [27], organisational capabilities are embedded in organisational routines, structures, and processes. Accordingly, routines could be a source of ambidexterity. Routines are found in the way the organisation operates. According to Winter [43], an organisational capability is a "high level routine (or collection of routines) that, together with its implementing input flows, confers upon an organisation's management a set of decision options for producing significant outputs of a particular type". Capabilities are associated with putting resources into action. Moreover, some academic articles describe operational capabilities as a bundle of routines, thereby broadening the focus on routines in the literature on organisational capabilities [44].

\subsubsection{Routines Derived from Standardisation of Work Processes and Organisational Ambidexterity}

Standardisation of work ensures automatic coordination through routines that formalize actions, reducing undesired variation, but also anticipating actions allowing desired variation [16]. Standardisation of work processes implies creating rules and guidelines stipulating the way decisions and actions are to be carried out [37]. Routines implementation creates the necessary adaptation and change, as the performative side of the routines requires the specific decisions of specific people who bring routines to life [17]. The interplay between structural and practical aspects of routines can generate a wide range of outcomes, from stability to considerable change [17], creating a context for sustainable organisational ambidexterity.

Enabling routines are designed with the participation of employees, and implemented and improved by employees $[45,46]$. These routines support workers exploiting accumulated knowledge when tasks require repetition and taking explorative decisions when new information or knowledge is needed [18,47].

Some routines are defined as meta-routines which are "routines for changing other routines" that facilitate "the efficient performance of non-routine tasks", and "shift the tradeoff by transforming no routine into more routine tasks" [34] (p.45). PDCA (Plan, Do, Check, Act), also known as the Deming wheel or the continuous improvement cycle, is a methodology companies use to facilitate planning, control, and process improvement. It is a type of meta-routines facilitating the improvement and changeover of routines and can even generate capabilities such as ambidexterity by driving learning in organisations through the flexible implementation of enabling routines [48].

\subsubsection{Standardisation of Skills and Sustainable Organisational Ambidexterity}

Standardisation of skills is a coordination mechanism which can create a context where decisions are based on expertise. Skills are standardised when the kind of training required to perform the work is specified for a specific work [16]. When standardisation of skills is used as coordinating mechanisms, it is possible to anticipate worker's actions, and peers know what to expect from each other $[16,37,38]$.

Skilled personnel play a crucial role in the balancing of exploitation and exploration with the help of their cognitive skills and technical knowledge [13]. Knowledge workers search knowledge from memory (performing routine job), as well as from external sources (scanning for new information or knowledge), to keep their firms competitive [13,49]. Skilled workers are highly sensitive to change and they can explore, with equivalent attention on current capabilities, working in a complex and challenging environment $[13,47]$.

Standardisation of skills creates a context for sustainable ambidexterity supporting people to make decisions to attain goals being efficient while adapting to change. Ambidexterity at Toyota was attributed to the problem-solving skill of employees at all levels $[13,28]$. 


\subsubsection{Standardisation of Results and Sustainable Organisational Ambidexterity}

Standardisation of results aligns people towards achieving goals and it is a source of automatic coordination [16]. Standardisation of results is a mechanism requiring individuals to engage in those activities to achieve the outcome expected, and therefore creating a context for efficiency and adaptability to environment changes $[37,38]$. Routines derived from standardisation of results will affect employee behaviour. These routines could act as a context to support workers to develop their creative ideas to attain goals when they feel they are trusted, as well as have the freedom to engage in improvement initiatives [18].

In Figure 1 we present the conceptual framework of the study derived from the literature review. Following Miles and Huberman [50], this conceptual framework serves as an anchor for the study and for data interpretation. The framework is developed through case studes, as we explain in the following section.

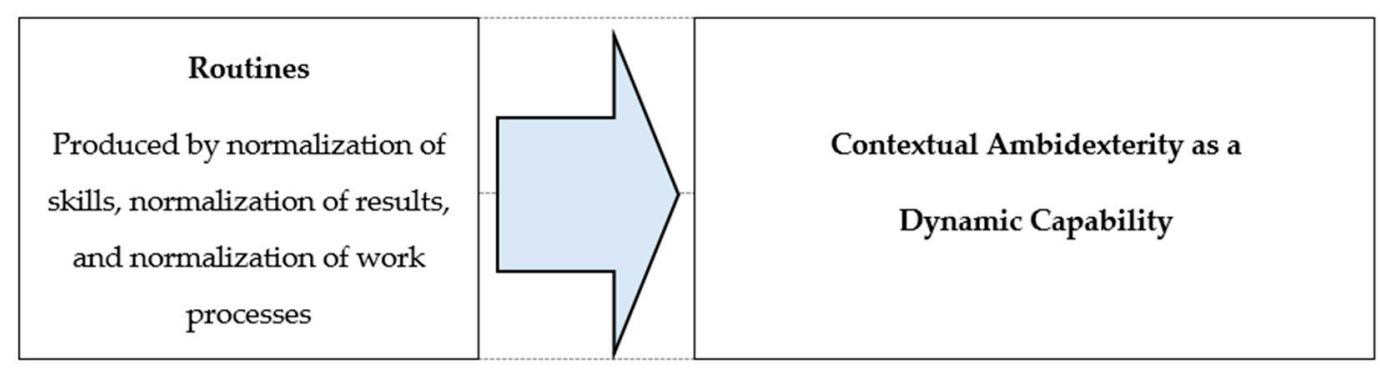

Figure 1. Conceptual framework of the study.

This conceptual framework includes the main concepts presented in the literature review. These concepts are defined in Table 2. As there are multiple conceptualizations of these concepts in the literature, we clarify the terminology and definitions used in this article.

Table 2. Main concepts of the study.

\begin{tabular}{|c|c|}
\hline Concept & Definition \\
\hline $\begin{array}{l}\text { Organisational } \\
\text { Ambidexterity }\end{array}$ & $\begin{array}{l}\text { "The firm's ability to integrate, build, and reconfigure internal and } \\
\text { external competencies to address rapidly changing environments" }\end{array}$ \\
\hline Dynamic capability & $\begin{array}{l}\text { (Teece, Pisano \& Shuen, 1997, p. 516). } \\
\text { "Behavioural capacity to simultaneously demonstrate alignment and } \\
\text { adaptability across an entire business unit. Alignment refers to the } \\
\text { coherence among all the patterns of activities in the business unit; }\end{array}$ \\
\hline Contextual Ambidexterity & $\begin{array}{l}\text { they are working together toward the same goals. Adaptability } \\
\text { refers to the capacity to reconfigure activities in the business unit } \\
\text { quickly to meet changing demands in the environment." } \\
\text { (Gibson and Birkinshaw, 2004, p. 209). [15] }\end{array}$ \\
\hline Organisational Capabilities & $\begin{array}{l}\text { "High level routine or collection of routines that, together with its } \\
\text { implementing input flows, confers upon an organisation's } \\
\text { management a set of decision options for producing significant } \\
\text { outputs of a particular type" (Winter, 2003, p. 991). [43]. }\end{array}$ \\
\hline Exploitation & $\begin{array}{l}\text { "Exploitation includes such things as refinement, choice, production, } \\
\text { efficiency, selection, implementation, execution" } \\
\text { (March, 1991, p. 71) [21]. }\end{array}$ \\
\hline Exploration & $\begin{array}{l}\text { "Exploration includes things captured by terms such as search, } \\
\text { variation, risk taking, experimentation, play, flexibility, discovery, } \\
\text { innovation" (March, 1991, p. 71) [21]. }\end{array}$ \\
\hline Routines & $\begin{array}{l}\text { "Repetitive, recognizable patterns of interdependent actions, carried } \\
\text { out by multiple actors" (Feldman and Pentland, 2003, p. 95) [17]. }\end{array}$ \\
\hline & $\begin{array}{l}\text { Standardisation as a means to coordinate work by clearly defining } \\
\text { the roles of each participant. Standardisation has three components: } \\
\text { - input skills: training required to perform the work is specified }\end{array}$ \\
\hline \multirow[t]{2}{*}{ Standardisation of work processes, results, and skills. } & - work processes: contents of the work are specified or \\
\hline & $\begin{array}{l}\text { - outputs: the results of the work are specified } \\
\text { (Mintzberg, 1979, pp. 3-9) [16]. }\end{array}$ \\
\hline
\end{tabular}




\section{Research Methods}

We set out our empirical study to explore four case studies of IT service companies. Our unit of analysis for understanding the connection between the concepts was the organisation. We were interested in the organisational design, the organisational context, and organisational behaviour in respect to the routine-capability connection we intended to study.

Case studies are a valuable method for our theoretical development, following previous literature [51]. As stated by Gavetti et al. [48], case studies are still important in developing new theory in this tradition and have been very useful to advance the theory of organisational routines [49]. There is a lack of research regarding the empirical connection between routines and ambidexterity. To address this gap, we used exploratory case studies to empirically analyse the above discussion.

Case study methodology provides tools for researchers to study complex phenomena within their contexts. It allows researchers to explore organisations through complex interventions, relationships, communities, and programs [52], and supports the deconstruction and the subsequent reconstruction of various phenomena. This main strength of this methodology is that it measures and records behaviour, as well as allows us to use a variety of data sources, such as documentation, archival records, interviews, and direct observation [52]. According to Yin [52], there are different types of case studies, the exploratory type is the case study used to explore the situations in which the intervention under evaluation has no clear, single set of outcomes [52].

Qualitative methodology is considered to be the best choice to enlighten us to answer the research questions, as it allows us to conduct a detailed examination of the particularity of this scarcely researched issue. Moreover, as the literature points out, a case study design should be considered when the focus of the study is to answer "how" and "why" questions and contextual conditions are going to be covered [52]. As all these circumstances concur in this study, the case study methodology was chosen.

The role of the conceptual framework [50] is very important for the analysis. These authors noted, "the conceptual framework serves several purposes: (a) identifying who will and will not be included in the study; (b) describing what relationships may be present, based on logic, theory and/or experience; and (c) providing researchers with the opportunity to gather general constructs into intellectual bins" [50] (p. 18). The conceptual framework serves as an anchor for the study and is referred to at the stage of data interpretation.

The explorative analysis took place between November 2018 and January 2019, in four IT consultancy companies, two medium-sized companies (one based in United Kingdom and the other based inSpain) and two large-sized companies (one based in France and the other based in the USA). All firms offer IT consultancy services to create ad hoc financial planning and accounting systems for other companies. Their solutions are built on standard software supplied by an external software provider. Their clients are companies of all sizes and in all industries for whom they develop ad hoc projects.

All of these IT service companies have quality management systems and hold the ISO 9001 certificate. The foundation of their business, i.e., technology, is constantly changing. Projects are ad hoc, requiring a high degree of adaptability to the market. Therefore, the companies must understand each client's particular problems before they can resolve them. We selected these four companies for the following reasons: (1) the availability of information, since all companies were willing to take part in the study; (2) all of them have implemented a quality management system, and therefore they have developed routines and procedures in the framework of this system; (3) all of them belong to a dynamic sector, i.e., IT consultancy, and therefore need to be ambidextrous; (4) all companies have characteristics which are typical of the sector; (5) they have different sizes (two of them are medium-sized and the other two are large-sized); and (6) all of them are based in different countries, enriching the study for their cultural diversity.

This section provides a detailed description of the steps involved in the case study research and the methods used to achieve validity and reliability following relevant literature on qualitative research 
methods [53-55]. Firstl, the case study protocol was designed (see Appendix A). Then, the companies were selected and invited to participate in the study. Information on the companies came mainly from semi-structured interviews and analysis of documentation, in line with the protocol. We selected interviewees for their knowledge, and for their involvement in different tasks, such as software design, assessment, testing, installing, and maintenance. We interviewed the following employees (see Table 3):

Table 3. Case analysis interviews.

\begin{tabular}{cccc}
\hline Company & Interviewees & Interviews & Total Time \\
\hline A & Development consultant & 1 face-to-face/1 virtual & $70^{\prime}$ \\
A & Support engineer & 1 face-to-face/1 virtual & $65^{\prime}$ \\
B & Development consultant & 2 face-to-face/1 virtual & $65^{\prime}$ \\
B & Head support department & 1 face-to-face/1 telephone call & $60^{\prime}$ \\
C & Development consultant & 1 face-to-face/1 virtual & $80^{\prime}$ \\
C & Support engineer & 1 face-to-face/1 virtual & $45^{\prime}$ \\
D & Development consultant & 2 virtual & $65^{\prime}$ \\
D & Support engineer & 2 virtual & $60^{\prime}$ \\
\hline
\end{tabular}

Company A (UK), medium-sized (a) Development consultant, one face-to-face interview and one interview via Skype. (b) Support engineer, one face-to-face interview and one interview via Skype. In both cases, there were several email exchanges before and after the interviews.

Company B (Spain), medium-sized (a) Development consultant, two face-to-face interviews and one telephone call. (b) Head of the support department, one face-to-face interview and one telephone call. In both cases, there were several email exchanges before and after the interviews.

Company C (France), large-sized (a) Development consultant, one face-to-face interview and one interview via Skype. (b) Support engineer, two interviews via Skype. In both cases, there were several email exchanges before and after the interviews.

Company D (USA), large-sized (a) Development consultant, two interviews via Skype. (b) Support engineer, two interviews via Skype. In both cases, there were several email exchanges before and after the interviews.

Interviews were considered to be the primary gathering source for the research. The interviews were recorded after consent was given by the interviewees and were transcribed within $24 \mathrm{~h}$ of their occurrence to avoid losing data, and more importantly, to secure a correct interpretation of the dialogues. The interviews allowed a collection of spontaneous responses through the interaction between the interviewer and the interviewee, thus avoiding problems related to the interpretation of the questions asked. We maintained a tone of sympathetic objectivity throughout the study, trying to minimize any social desirability bias in what interviewees reported to us [56].

To ensure validity and reliability we adhered to the case study protocol and interview guide (Appendix A). The interviewees were initially informed about the research questions and objectives. Questions were carefully designed to deliver ample coverage for the aims of the research and to combine enough flexibility to approach interviewees in a different way, while covering the same areas of information allowing individual responses to guide further questions.

Moreover, we collected different documentary sources such as Internet documents, company reports, published journal interviews, official papers, and other similar materials that were made available for the purpose of the research. We had access to quality management procedures, i.e., IT professionals' job descriptions, public documentation on the companies' services, products, and internal organisation that was accessible through their websites. Documents where considered to be a source of supplementary information, as well an adequate tool to cross validate information from interview and direct observation. Corroboration of multiple qualitative techniques enhances the validity and reliability of findings [53-55].

Data derived from the interviews were transcribed and used for analysis. To conduct the document analysis, first, we carried out an overall consideration, to continue with an in-depth examination and 
analysis to discover themes related to the study [55]. The transcripts were integrated and triangulated to allow checking of the judgment provided by the various respondents. If required, additional information from the interviewees was sought through email and phone interviews.

Following Siedel and Kelle (1995) [57], we used coding to notice relevant phenomena, gathering examples of those phenomena and analysing those phenomena in order to discover commonalities, dissimilarities, patterns, and structures. We created a provisional list of codes prior to the fieldwork, determining the coding system to enhance validity and certainty of the findings [58]. This list derived from the conceptual framework included the following: For organisational ambidexterity (OA)/adaptation, balance; for exploitation (EX)/execution, efficiency, selection, implementation, and improvement; for exploration (ER)/search, flexibility, experimentation, risk taking, and variation; for standardisation of work processes (SWP)/plans, guides, rules, and procedures; for standardisation of results (SSR)/outputs, results and goals; for standardisation of skills (SSS)/inputs, training and learning; for routines (RR)/repetition, patterns; For enabling (EN)/support, participation and trust; for coercive/obligatory, rigid and constrain; ostensive/structural, stabile; for performative/practical, variable.

Both researchers reviewed all the data to form independent views and we synthesized these views with the case for each firm [53-55]. The cross-case analysis considered the constructs and themes in the cases and began after most data had been collected in order to preserve the integrity of replication logic across cases [59]. We highlighted similarities and differences, frequently returning to each case to corroborate the occurrence of relationships and logics [58]. The findings can be considered to be robust as they are derived from four case studies [60]. We engaged in several iterations among data, literature, and theory, until we had a match between theory and data. We triangulated data collected from various sources at different times reinforcing confidence in the exactitude of findings. Therefore, we could emphasize themes that were supported by different data collection methods and confirmed by several informants [61].

The theoretical framework was completed as the study progressed exploring different explanations. The final conceptual framework included all the themes that emerged from data analysis To stablish credibility, we included collaborative reflection at the analysis stage, to improve the consistency of the findings. As recommended by Baxter and Jack, both researchers discussed their thoughts and decisions between them, and with several members of the research team, to avoid being driven by the framework and limiting the inductive approach when exploring the case studies. We attempted to understand the overall case, instead of looking at different parts of the case individually.

\section{Results}

This section explains the findings of our study with reference to establishing the connection between routines and ambidexterity, as proposed in the previous theoretical section. To understand the routines in these companies and how they were developed, applied, and improved, creating a context in which exploitation and exploration can be simultaneously developed, we focused our analysis on the operational departments (the development department and the support department). Technically, the work in the development department in all companies consists of customising the standard software to adapt it to the client's needs. The development consultants, previously, have to ascertain whether the client's IT infrastructure will allow the system to function optimally. The support department responsibility begins after the system has been installed and tailored to the client's needs. This department may simply resolve any technical issues that arise, which would be classed as support tasks, or may take complete responsibility for administering the system, depending on the contract with the client.

We found several common characteristics in all companies in terms of employees' professional profiles, tasks, and organisation. The development department in the four firms is composed of highly qualified, experienced professionals. Most development consultants are IT engineers or economists. They normally work in teams to pool competences and experience. The teams are created ad hoc for 
each project, and there is a project coordinator who reports to the client. The exploratory content of tasks in the development department is high, because the development consultants seek new business solutions to satisfy customer needs. Nevertheless, consultants also have exploitative tasks, for example, as the development consultant in company D explains: "Each project is different, although we (development consultants) usually have access to documentation from previous projects".

The support department in the four companies is composed of IT experts with differing degrees of experience, and also highly qualified. Interviewed support engineers agreed that their work is less creative than that of the development department, although they also require a certain degree of creativity to ascertain the cause of issues and to find appropriate solutions. When asked to assess the balance between exploration and exploitation activities, the interviewees, from all four companies, agreed that they had to be good at both explorative and exploitative tasks, but they gave exploration a lower score in the support department. As the support engineer in company A stated, "Creating a system is mainly exploratory; maintaining it is mainly exploitative". The support engineer for company D explained, "Our department focuses on maintaining a previously designed solution, so it is not usual to search for new knowledge".

We also found some difference in the balance between exploration and exploitation activities depending on the size of the companies. When interviewees were asked to estimate the time spent on exploratory rather than exploitative activities, the figures for the four companies were different. Medium-sized firm respondents reported that they spent most of their time on exploratory rather than exploitative activities. As a development consultant we interviewed in company A, told us, "Each of our clients has its own internal way of doing things, so each project means we have to explore and learn new knowledge. Our activities are basically exploratory, and although we do use previously known software analysis and development methods, we always have to individualise them for each client". In contrast, consultants interviewed in large-sized companies reported a different view. In company C, the consultant stated, "It is difficult to propose novel solutions that do not conform to what the company has previously offered". In addition, in company D, the consultant declared, "The dedication in my company is very specialized and this does not facilitate finding very innovative solutions". However, both consultants from companies $C$ and $D$ agreed that they use the latest advances in technology and adapt them to the client, so they have to be updated and need to explore custom solutions. Consultant $C$ also argued, "In the case that there are no previous projects that adapt to the needs of new projects, we need to explore new ways to give a solution to the client". As compared with medium-sized firms, large-sized firms revealed a lower level of exploration due to their degree of specialization, but in both types of companies, case study findings showed a combination of exploration and exploration for the same unit.

\subsection{Standardisation of Work Processes}

In terms of standardisation of work processes, the data analysis results show a high level of standardisation. There are many rules and guidelines developed to stipulate what actions and decisions are to be carried out. On the one hand, these are not coercive standards, on the other hand, they are enabling standards. In all four companies, we discovered the existence of general routines guiding the tasks of IT professionals. For example, there are routines regulating the work processes at the development department as consultants need to adhere to the following phases of project development: (1) pre-analysis, (2) sales agreement, (3) analysis, (4) design, (5) implementation, and (6) testing of the implemented system. IT professionals in the development department have to provide all the deliverables previously agreed with the client for each phase.

In terms of explicit routines related to the standardisation of work processes, we found the existence of project guidelines. These guidelines are drawn up by consultants in the development department. There are three types of guidelines associated with the projects, two of the guidelines are delivered to the client (user and administrative guidelines) and one guideline is used by the support department (support project guide). The user guidelines are used by the client company's employees 
to understand the IT system, and the administrative guidelines are used by the person in charge of the implemented system. These guidelines depend on the terms of the contract agreed with the client and are only compulsory if the client requires them.

The third guide, i.e., the support project guidelines, drawn up by the development department, is used by the support department and regulates and coordinates both departments' relationships and aims to improve the work of support engineers. A development consultant in company A explained, "In the case of the development department, the first thing to do is to learn about the client company. You have to document the whole process and develop solutions through exploration. In the case of the support department, the development consultants have already created the documentation and therefore this department has to study it in a process that is usually already well established and regulated".

The guidelines allow exploitation of knowledge, as they are repositories of the organisation's memory, and support the organisations to efficiently meet their goals. But they are not coercive; they allow professionals to decide whether to follow them or to explore other solutions. Exploration refers to seeking new ways (i.e., new software design) to existing or new clients. For example, the support engineer form company $\mathrm{C}$ explained, "Some clients raise a problem that we have not yet dealt with. Then we need to be creative. On one occasion we had to combine two software designs to meet the client needs". Therefore, they are an enabling form of formalised routine [18], because they guide the experts rather than control them. These guidelines and protocols are totally ad hoc. They are produced by consultants, not by the top management, when they are needed, based on the consultants' professional judgment.

Engineers in the support department use the user and administrative guidelines for the specific product design of each client and the support project guidelines to solve issues that may arise from poorly functioning hardware or programs. Experts from the development departments write these protocols. Nevertheless, support engineers have full autonomy to resolve issues. According to one support engineer from company A, "you manage the situation however you can; as long as you resolve the issue, it doesn't matter what you do". Support engineers sometimes ignore these guidelines and instead search for a solution online, ask other engineers or report an issue to the software provider. Any approach is valid as long as they resolve the issue as soon as possible. This freedom to implement explicit routines is linked to the theory put forward by Feldman and Pentland [17] on the differentiation between the performative and ostensive aspects of routines.

Support engineers also have access to documentation on previous projects and use these voluntarily. They are also free to introduce as many changes as they think are necessary, according to the changes made in the implemented system. Additionally, an engineer from the support department in company A reported that many project guidelines are incomplete and overly generic, because consultants have a certain resistance to establishing protocols, as this is considered to constitute a non-creative task. In company $\mathrm{C}$, although general project guidelines need to be followed, it is frequent that support staff explore new ways to address problems.

Furthermore, as part of the quality management methods, process quality improvement methodologies help consultants to achieve better results. For example, at company A, the development consultant explained, "We usually bring in another consultant before the end of the project to review what the development team has done". The final assessment of each project is another routine the four companies have in common. It includes a meeting with the team that has developed the software and a final report. As a development consultant in company B stated, "This meeting is very important although sometimes time pressure does not allow us enough reflection about the project". In company $\mathrm{D}$, another development consultant told us, "Meetings at the end of each project allow us to review the final results".

From this explorative analysis, we can conclude that there are many explicit procedures produced by the standardisation of work processes to regulate consultancy tasks. These procedures are enabling [18] and are adapted depending on the particular scenario in which they are applied [17]. 
The professionals do not need to follow these procedures strictly; they make their own decisions with no need for supervisor approval, deciding in each situation whether to explore or to exploit. Figure 2 shows the findings of the case studies regarding the connection between standardization of work processes and routines.

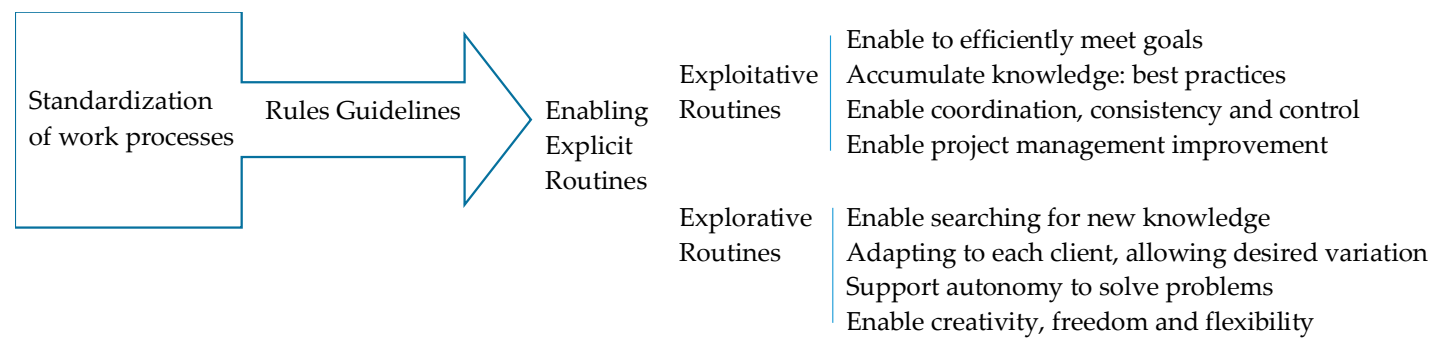

Figure 2. Standardisation of work processes and routines.

\subsection{Standardisation of Skills}

The case study findings show how standardisation of skills creates a context for sustainable organisational ambidexterity. In terms of what Mintzberg [16] calls the standardisation of skills, and as was to be expected, given the professional nature of these organisations, we found implicit routines that were embedded in consultants' and engineers' capabilities and that had been acquired through training and experience to be extremely important. The professionals at the development and support departments are highly qualified and experienced. Development professionals normally work in teams created for each project to share competences. A project coordinator reports to the client. Development teams are trusted to decide whether to take exploitative decisions, using previous knowledge, or explorative ones, seeking new solutions to satisfy customer needs. It is considered that their expertise permits them to find the adequate solution for their customers, and they are particularly motivated to explore, if previously used tools do not meet the need.

Support engineers' work requires more exploitation and less creativity than development engineers' work. The capability to tackle new situations and to creatively respond to these situations are higher in the development department. However, support engineers are also highly trained professionals, who are somewhat dissatisfied that their knowledge does not give them an overview of the service. According to the head of the support department in company B, “Knowing why a car doesn't turn to the left properly doesn't make you a better driver". The imbalance towards exploitation in these support departments demotivates the professional highly skilled staff.

In these departments, we found that the work of IT professionals is highly directed and conditioned by their previous training, which is acquired mostly through experience in projects as a result of shadowing more experienced consultants and engineers. As stated by a development consultant in company B, "We receive training in the company. There are many changes in the technologies, and we need to keep up to date. The way to justify the decisions taken and how to explain them to the clients is also learned in the company". Moreover, a development consultant in company C argued, "We are constantly trained, and we continuously learn from our daily challenges. We need to keep up with the latest technologies, so training is fundamental in our profession". Figure 3 shows the findings of the case studies regarding the connection between standardization of skills and routines. 


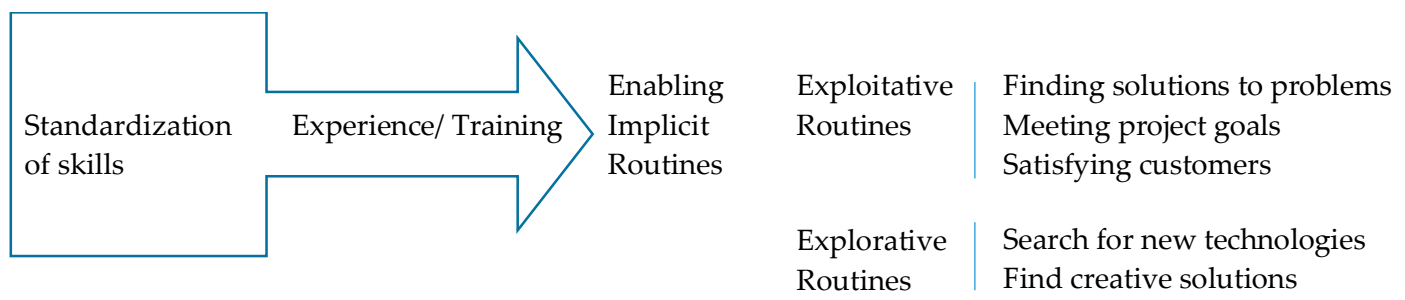

Figure 3. Standardisation of skills and routines.

\subsection{Standardisation of Results}

The description and findings of the case analysis provide evidence to support the relevance of standardisation of results, creating a context for sustainable organisational ambidexterity. In all the cases, we found in common that there was an emphasis on achieving the goal of customer satisfaction. In these companies, the consultants must find the way to satisfy customer needs, meeting deadlines and providing quality services, adapted to the customer's needs.

We found that consultants have autonomy to suggest new ways of doing things. Development consultants might develop a new software and use another programming language, because previous business solutions are not enough appropriate. As the development consultant in company D explains, "We need to find the best solution for our customers, so we are motivated to explore, if previously used tools do not meet the need".

IT professionals have a large degree of freedom as long as they obtain the results they need to meet their customers' needs. Usually, consultants and engineers are under pressure to meet clients' demands on time. They must use their professional judgment to guide their decision making to satisfy clients and to comply with the services they have agreed to provide them with. As the head of the support department in company B explains, "We understand it is our responsibility to find the adequate solutions to provide customers what they need". In company A, the development consultant referred to the fact that before undertaking a new project they (the team in charge of the project) organise meetings to analyse previous best practices, but only when they have time. As he explained it, "Everything depends on the time available, and normally we are under pressure to meet client deadlines".

Several protocols govern how engineers in the support department should act to resolve issues reported by clients. First, a time protocol sets a deadline for resolving an issue. This deadline varies depending on the issue's severity. Failure to resolve the issue before the deadline may result in the client imposing a penalty, depending on the terms stipulated in the contract. We find that in responding adaptively to customer needs, professionals shift between activities to accentuate exploitation or exploration to achieve the desirable high levels of both adapting and implementing routines to improve customer satisfaction. Figure 4 shows the findings of the case studies regarding the connection between standardization of results and routines.

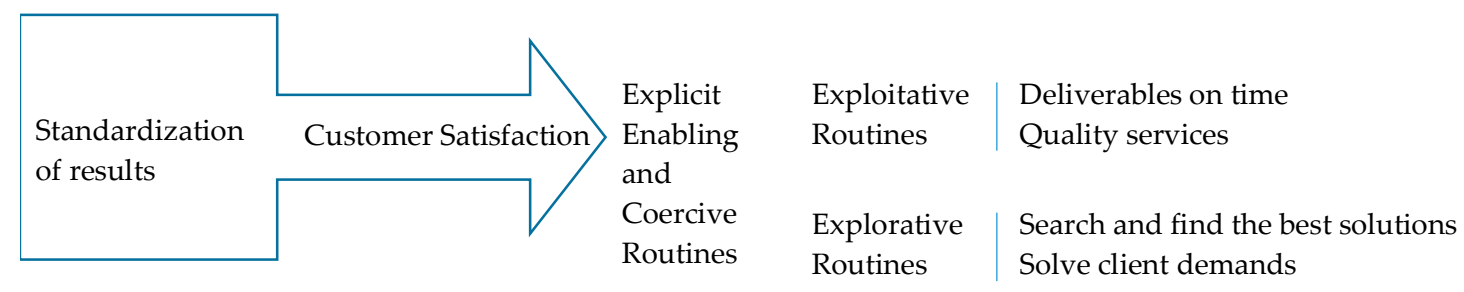

Figure 4. Standardisation of results and routines.

In Figure 5, we present a general view of the case studies findings. The organisational capabilities, i.e., exploitation and exploration, are developed at the operational level from a bundle of routines [44] derived from standardisation of work processes, skills, and results. Routines support workers exploiting accumulated knowledge when tasks require repetition and taking explorative decisions when new 
information or knowledge is needed. Successful management of exploitation and exploration allows them to develop ambidexterity as the dynamic capability to use exploitation and exploration to efficiently adapt to external requirements.

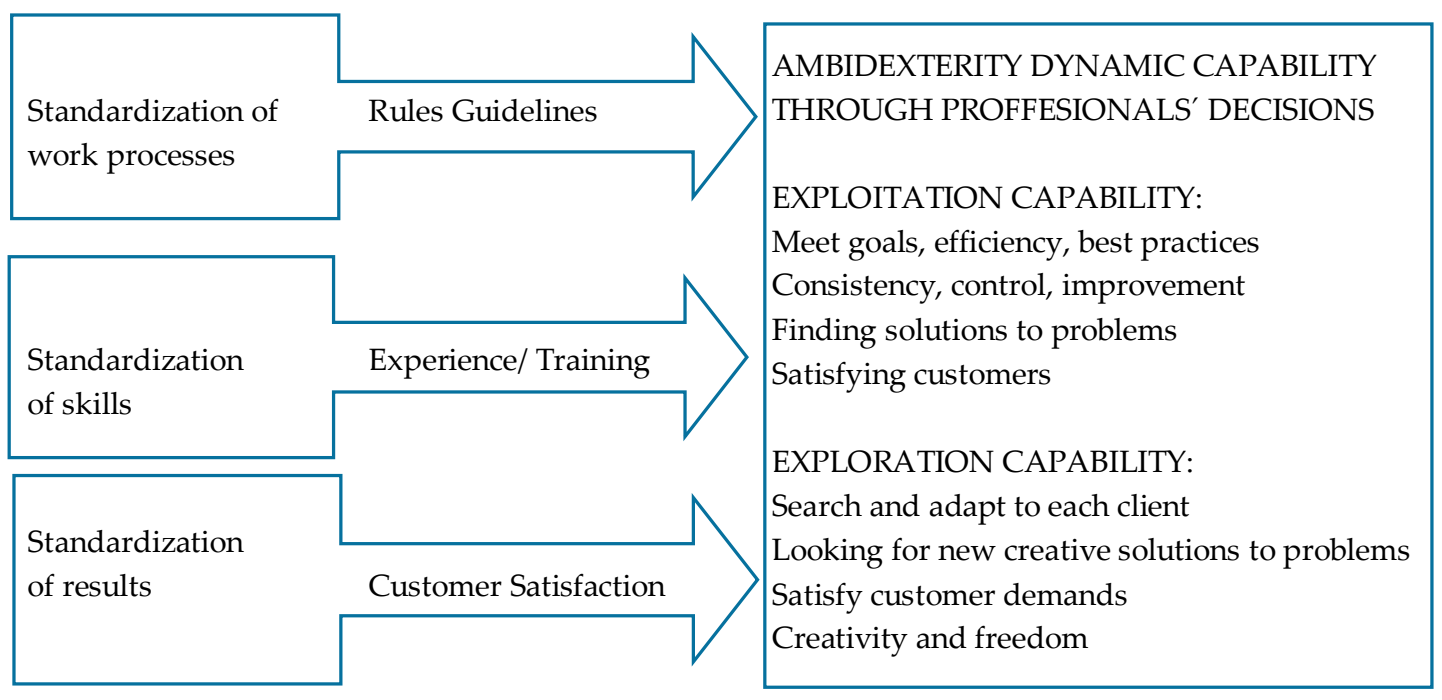

Figure 5. Standardisation, routines, and capabilities.

\section{Discussion}

In recent years, there has been an explosion of publications on ambidexterity. Many prestigious management journals have turned their attention to the topic. Some journals have devoted special issues to the area such as Academy of Management Journal, 2006; Organisation Science, 2009; and Academy of Management Perspectives, 2013. Some scholars even called it an emerging paradigm in organisational theory [24-26], and a promising research stream [2,27].

However, after such an explosion of research and publications on the issue, there is still a need to understand how firms can develop contextual ambidexterity, which is the result of designing and establishing processes and systems that encourage employees to allocate time to different activities, either by continuing previous activities or changing to meet environmental demands [15]

Our paper explores the connection between routines and ambidexterity as a dynamic capability, by examining the breadth of the phenomenon and looking at the wide array of possibilities ranging from simple routines to dynamic capabilities. Our research moves forward on the recent debate around the concept of ambidexterity [3] and contributes to this literature in three major ways.

First, we appreciate that the boundaries between routines and capabilities become blurred, because capabilities are formed mainly by routines learnt through training or experience, confirming the perspective that routines stem from knowledge [8,31].

Secondly, previous research on ambidexterity asserts that structural ambidexterity requires ambidextrous managers or management teams that are capable of hierarchically coordinating specialist exploration and exploitation units [2,27]. In our paper we explore the connection between routines and ambidexterity as a dynamic capability, moving forward on the recent debate around the concept of ambidexterity [2,3]. The thread of our analysis of routines, following the logic of Mintzberg [16,36-38] in defining three types of normalisation, has been of great value. We found evidence of the normalisation of work processes that adopts the form of enabling procedures $[4,18]$ that are implemented in a very loose way. The normalisation of skills is also very relevant in this study, as it provides the implicit routines for IT professionals to distinguish between exploring or exploiting existing ones. Normalisation of results is also important, as it compels IT professionals to comply with the requirements of customers and deadlines. These three types of normalisation generate routines and meta-routines that contribute to set the context for organisational ambidexterity. 
We observed is that IT professionals make decisions according to the routines derived from standardisation of work processes and skills, but they have the freedom to decide what is to be done in each situation, as long as this takes into account customer satisfaction as the bottom line. In the case studies, we observed enabling routines create a context for ambidexterity aligning the organisations efficiently meet their goals. These routines support workers exploiting accumulated knowledge when tasks require repetition and taking explorative decisions when new information or knowledge is needed $[13,45]$. Routines guide the work of professionals and are carried out with total freedom. This freedom to implement explicit routines is also linked to the differentiation between the performative and ostensive aspects of routines posited by Feldman and Pentland [17]. We observed the importance of the professional's role in bringing routines to life to achieve organisational ambidexterity. Moreover, we found that this performative aspect of routines maintains the creativity of employees, generating motivation and commitment. Interestingly, our findings also reveal that firm size matters, and large-sized firms suggest a lower level of exploration in contrast to medium-sized firms, where employees feel freer to choose novel solutions tailored to meet customer's unique circumstances.

The ambidextrous capability is developed by IT professionals at the base of the hierarchy, not at upper management level. Professionals perform their work in a context that promotes ambidexterity. Normalisation of results has an important role, setting a context where customer satisfaction is a priority. Consultants seek to design the best solutions tailored to the needs and expectations of clients, whilst support engineers seek to resolve incidents as effectively as possible. This customer orientation requires professionals from both departments to make decisions about when to open up new paths, exploring new solutions, or when to refine earlier solutions to adapt them to new situations.

We find that implicit routines (standardisation of skills) and enabling explicit routines and meta-routines (procedures, guidelines and improvement processes) are crucial to achieve contextual ambidexterity in these companies. These routines, as well as the standardisation of results (customer satisfaction), play an important role in balancing exploratory and exploitative activities, because they support employees when making the decision to look for new knowledge and systems or when to improve existing ones.

From the findings mentioned above, we can conclude that, in these cases, contextual ambidexterity is developed thanks to the routines implemented by professional employees with a high degree of freedom. We found that consultants and engineers in both departments have full autonomy to resolve issues. The decision on whether to exploit or explore with the goal of meeting customer demands is made at the level of each highly qualified staff member on the project teams. This freedom to opt for exploitation or exploration is greatly facilitated by the employees' superior skills, which enable them to choose the most appropriate option in each case.

We understand our findings are applicable to IT companies, because the changing nature of technologies compels these firms to deliver accurate and refined services and, at the same time, adapt to continuous and rapid advances in technology. Professional judgment requires finding a balance between exploiting existing solutions and exploring new ones, supporting the organisations efficiently meet their goals.

In our analysis, we have seen that it is of great interest to look further into the contextual connection between routines, meta-routines, as well as the capabilities of exploration, exploration, and ambidexterity, since this link has not been explored thoroughly in the literature on ambidexterity. Therefore, we encourage the development of future studies on this phenomenon.

For practitioners, this study also brings important insights on how to create a context where routines derived from automatic coordination mechanism support ambidexterity. In our view, it is necessary to continue investigating the role of employees in achieving ambidexterity, especially in the case of highly qualified professionals, as they can play an important role in this area, and their case may be different from that of other types of employees. 
Author Contributions: Conceptualization, M.G.-M. and M.D.M.-L.; methodology, M.G.-M. and M.D.M.-L.; investigation, M.G.-M. and M.D.M.-L.; writing, M.G.-M. and M.D.M.-L. All authors have read and agreed to the published version of the manuscript.

Funding: This research was funded by the following institutions: the Universidad Católica de Valencia "San Vicente Mártir" (Management and Human Resources Research Group - UCV 238); the University of Valencia (Estudio General) (Quality Management, Innovation and Learning Group, ref. GIUV2015-257); and project ECO2015-71380-R funded by the Spanish Ministry of Economy, Industry and Competitiveness and the State Research Agency, co-financed by the European Regional Development Fund (ERDF).

Acknowledgments: The authors would like to acknowledge Paul Adler for the helpful comments and suggestions related to a previous version of the article. The authors would like to acknowledge the constructive suggestions made by the reviewers.

Conflicts of Interest: The authors declare no conflict of interest.

\section{Appendix A. Case Study Protocol}

1 Introduction to the research topic

The aim of this research is explaining how organisational routines and capabilities are connected. How can routines support the operational operations to achieve organisational goals, as well as adaptation and change?

2 Characteristics of the cases to be selected and the selection process

Representative IT companies willing to participate in this study. Their operations managers will be contacted to find out if they are willing and interested in participating in the study.

3 Material collection procedures

Interviews: Two members of the operational department will be interviewed. The interviews will last approximately one hour and will be structured by means of a general guide, although respondents will be encouraged to add any topic of interest not included in the guide. If possible, and provided that the interviewee agrees, the interviews will be recorded.

Documentation: We will collect additional documentation to expand on the information obtained in the interviews, so we will refer to the company's website, Internet documents, company reports, published journal interviews, official papers, and other similar materials.

Treatment of the information: With the information collected, he will build a case study. All individual and firm identities will remain confidential.

4 Topics to be covered in the interviews

About the interviewee: name/designation/company name, and location/department.

Specific questions derived from the main research question are the following:

What is the role of normalisation of work processes, skills and results to generate these routines in the company? Please describe.

What kind of normalisation exist in your company?

What are the rules governing the work in your company like?

How do you coordinate with other operational departments?

How are the rules designed?

Who participates in their creation?

What role does managerial supervision play?

What kind of routines do you follow to perform your work?

How do you apply and implement these norms, rules and procedures?

What routines exist in the company? By what means are these routines produced and maintained? Please describe.

What were the key objectives with which these were created?

Why are routines important in your company?

Why are they created? 
Are these routines defined in the company's rules and procedures?

Are they flexible or rigid? Are they compulsory or can they be adapted?

How can routines support the development of exploitation and exploration organisational capabilities? Please describe.

How do routines help you apply existing knowledge?

In which tasks do you use current resources and prioritize efficiency? Do they ensure the status quo of knowledge?

Are they a source of learning and change?

Are they useful for exploiting knowledge? Do they encourage the exploration of new knowledge?

How does your company balance between being effective in the short term while preparing for new challenges and changes?

\section{References}

1. Deng, P.; Liu, Y.; Gallagher, V.C.; Wu, X. International strategies of emerging market multinationals: A dynamic capabilities perspective. J. Manag. Organ. 2020, 26, 408-425. [CrossRef]

2. O'Reilly, C.A.; Tushman, M.L. Organizational Ambidexterity: Past, Present, and Future. Acad. Manag. Perspect. 2013, 27, 324-338. [CrossRef]

3. Wang, T.; Yang, J.; Zhang, F. The effects of organizational controls on innovation modes: An ambidexterity perspective. J. Manag. Organ. 2017, 2017, 10663. [CrossRef]

4. Adler, P.; Benner, M.; Brunner, D.J.; MacDuffie, J.P.; Osono, E.; Staats, B.R.; Takeuchi, H.; Tushman, M.L.; Winter, S.G. Perspectives on the Productivity Dilemma. J. Oper. Manag. 2009, 27, 99-113. [CrossRef]

5. Teece, D.J. Dynamic Capabilities: Routines versus Entrepreneurial Action. J. Manag. Stud. 2012, 49, 1395-1401. [CrossRef]

6. Kashan, A.J.; Mohannak, K. Integrating the content and process of capability development: Lessons from theoretical and methodological developments. J. Manag. Organ. 2017, 25, 748-763. [CrossRef]

7. Tushman, M.L.; O’Reilly, C.A. Ambidextrous Organizations: Managing Evolutionary and Revolutionary Change. Calif. Manag. Rev. 1996, 38, 8-30. [CrossRef]

8. Teece, D.J.; Pisano, G.; Shuen, A. Dynamic capabilities and strategic management. Strateg. Manag. J. 1997, 18, 509-533. [CrossRef]

9. Eisenhardt, K.M.; Martin, J.A. Dynamic Capabilities: What Are They? Strateg. Manag. J. 2000, 21, 1105-1121.

10. Kogut, B.; Kulatilaka, N. Capabilities as Real Options. Organ. Sci. 2001, 12, 744-758. [CrossRef]

11. Michelino, F.; Cammarano, A.; Celone, A.; Caputo, M. The Linkage between Sustainability and Innovation Performance in IT Hardware Sector. Sustainability 2019, 11, 4275. [CrossRef]

12. Junni, P.; Sarala, R.M.; Taras, V.; Tarba, S.Y. Organizational Ambidexterity and Performance: A Meta-Analysis. Acad. Manag. Perspect. 2013, 27, 299-312. [CrossRef]

13. Rao, I.; Thakur, P. Knowledge workers, organisational ambidexterity and sustainability: A conceptual framework. Int. J. Bus. Excel. 2019, 19, 415-428. [CrossRef]

14. Wan, X.; Cenamor, J.; Parker, G.; Van Alstyne, M. Unraveling Platform Strategies: A Review from an Organizational Ambidexterity Perspective. Sustainability 2017, 9, 734. [CrossRef]

15. Gibson, C.B.; Birkinshaw, J. The Antecedents, Consequences and Mediating Role of Organizational Ambidexterity. Acad. Manag. Rev. 2004, 47, 209-226.

16. Mintzberg, H. The Structuring of Organizations; Prentice Hall: Englewood Cliffs, NJ, USA, 1979.

17. Feldman, M.S.; Pentland, B.T. Reconceptualizing Organizational Routines as a Source of Flexibility and Change. Adm. Sci. Q. 2003, 48, 94-118. [CrossRef]

18. Adler, P.; Borys, B. Two Types of Bureaucracy: Enabling and Coercitive. Adm. Sci. Q. 1996, 41, 61-89. [CrossRef]

19. Wang, C.L.; Rafiq, M. Ambidextrous Organizational Culture, Contextual Ambidexterity and New Product Innovation: A Comparative Study of UK and Chinese High-Tech Firms. Br. J. Manag. 2014, 25, 58-76. [CrossRef]

20. Havermans, L.A.; Hartog, D.N.D.; Keegan, A.; Uhl-Bien, M. Exploring the Role of Leadership in Enabling Contextual Ambidexterity. Hum. Resour. Manag. 2015, 54 (Suppl. 1), s179-s200. [CrossRef] 
21. March, J.G. Exploration and Exploitation in Organizational Learning. Organ. Sci. 1991, 2, 71-87. [CrossRef]

22. Asif, M. Exploring the antecedents of ambidexterity: A taxonomic approach. Manag. Decis. 2017, 55, 1489-1505. [CrossRef]

23. Hirst, G.; Van Knippenberg, D.; Zhou, Q.; Zhu, C.J.; Tsai, P.C.-F. Exploitation and Exploration Climates' Influence on Performance and Creativity: Diminishing Returns as Function of Self-Efficacy. J. Manag. 2018, 44, 870-891. [CrossRef]

24. Raisch, S.; Birkinshaw, J. Organizational Ambidexterity: Antecedents, Outcomes, and Moderators. J. Manag. 2008, 34, 375-409. [CrossRef]

25. Raisch, S.; Birkinshaw, J.; Probst, G.; Tushman, M.L. Organizational Ambidexterity: Balancing Exploitation and Exploration for Sustained Performance. Organ. Sci. 2009, 20, 685-695. [CrossRef]

26. Simsek, Z. Organizational Ambidexterity: Towards a Multilevel Understanding. J. Manag. Stud. 2009, 46, 597-624. [CrossRef]

27. O'Reilly, C.A.; Tushman, M.L. Ambidexterity as a Dynamic Capability: Resolving the Innovator's Dilemma. Res. Organ. Behav. 2008, 28, 185-206. [CrossRef]

28. Lavie, D.; Stettner, U.; Tushman, M.L. Exploration and exploitation within and across organizations. Acad. Manag. Ann. 2010, 4, 109-155. [CrossRef]

29. Eltantawy, R.A. The role of supply management resilience in attaining ambidexterity: A dynamic capabilities approach. J. Bus. Ind. Mark. 2016, 31, 123-134. [CrossRef]

30. Lee, S.M.; Rha, J.S. Ambidextrous supply chain as a dynamic capability: Building a resilient supply chain. Manag. Decis. 2016, 54, 2-23. [CrossRef]

31. Nelson, R.R.; Winter, S.G. An Evolutionary Theory of Economic Change; Harvard University Press: Cambridge, MA, USA, 1982.

32. Pentland, B.T.; Feldman, M.S.; Becker, M.C.; Liu, P. Dynamics of Organizational Routines: A Generative Model. J. Manag. Stud. 2012, 49, 1484-1508. [CrossRef]

33. Becker, M.C. Organizational routines: A review of the literature. Ind. Corp. Chang. 2004, 13, 643-678. [CrossRef]

34. Adler, P.; Goldoftas, B.; Levine, D.I. Flexibility versus Eficiency? A Case Study of Model Changeover in the Toyota Production System. Organ. Sci. 1999, 41, 43-68. [CrossRef]

35. Cohen, M.D.; Bacdayan, P. Organizational Routines Are Stored as Procedural Memory: Evidence from a Laboratory Study. Organ. Sci. 1994, 5, 554-568. [CrossRef]

36. Mintzberg, H. Covert leadership: Notes on managing professionals. Harv. Bus. Rev. 1998, 76, 140-148. [PubMed]

37. Berniker, E.; Mintzberg, H. Structure in Fives: Designing Effective Organizations; Prentice Hall: Upper Saddle River, NJ, USA, 1983.

38. Rondeau, P.J.; A Vonderembse, M.; Ragu-Nathan, T. Exploring work system practices for time-based manufacturers: Their impact on competitive capabilities. J. Oper. Manag. 2000, 18, 509-529. [CrossRef]

39. Moreno-Luzón, M.D.; Lloria, M.B. The Role of Non-structural and Informal Mechanisms of Integration and Coordination as Forces in Knowledge Creation. Br. J. Manag. 2008, 19, 250-276. [CrossRef]

40. Gil-Marques, M.; Moreno-Luzon, M.D. Driving human resources towards quality and innovation in a highly competitive environment. Int. J. Manpow. 2013, 34, 839-860. [CrossRef]

41. Podsakoff, P.M.; Williams, L.J.; Todor, W.D. Effects of organizational formalization on alienation among professionals and nonprofessionals. Acad. Manag. J. 1986, 29, 820-831.

42. Chen, A.N.K.; Edgington, T.M. Assessing Value in Organizational Knowledge Creation: Considerations for Knowledge Workers. MIS Q. 2005, 29, 279. [CrossRef]

43. Moreno-Luzón, M.D.; Gil-Marques, M.; Valls-Pasola, J. TQM, innovation and the role of cultural change. Ind. Manag. Data Syst. 2013, 113, 1149-1168. [CrossRef]

44. Peng, D.X.; Schroeder, R.G.; Shah, R. Linking routines to operations capabilities: A new perspective. J. Oper. Manag. 2008, 26, 730-748. [CrossRef]

45. Hoy, W.K.; Sweetland, S.R. School Bureaucracies that Work: Enabling, Not Coercive. J. Sch. Leadersh. 2000, 10, 525-541. [CrossRef]

46. Winter, S.G. Habit, Deliberation, and Action: Strengthening the Microfoundations of Routines and Capabilities. Acad. Manag. Perspect. 2013, 27, 120-137. [CrossRef] 
47. Davenport, T.H. Thinking for a Living: How to Get Better Performances and Results from Knowledge Workers; Harvard Business Press: Boston, MA, USA, 2005.

48. Gavetti, G.; Greve, H.R.; Levinthal, D.A.; Ocasio, W. The behavioral theory of the firm: Assessment and prospects. Acad. Manag. Ann. 2012, 6, 1-40.

49. Pentland, B.T.; Rueter, H.H. Organizational Routines as Grammars of Action. Adm. Sci. Q. 1994, $39,484$. [CrossRef]

50. Miles, M.B.; Huberman, A.M. Qualitative Data Analysis: An Expanded Sourcebook; Sage: Oaks, CA, USA, 1994.

51. Cyert, R.M.; March, J.G. A Behavioral Theory of the Firm; Prentice Hall/Pearson Education: Englewood Cliffs, NJ, USA, 1963.

52. Yin, R.K. Case Study Research: Design and Methods, 3rd ed.; Sage: Thousand Oaks, CA, USA, 2003.

53. Ali, A.M.; Yusof, H. Quality in Qualitative Studies: The Case of Validity, Reliability and Generalizability. Issues Soc. Environ. Account. 2011, 5, 25-64. [CrossRef]

54. Golafshani, N. Understanding reliability and validity in qualitative research. Qual. Rep. 2003, 8, 597-607.

55. Meyer, C.B. A Case in Case Study Methodology. Field Methods 2001, 13, 329-352. [CrossRef]

56. Kahn, R.L.; Cannell, C.F. The Dynamics of Interviewing; Wiley: New York, NY, USA, 1957.

57. Siedel, J.; Kelle, U. Different Functions of Coding in the Analysis of Textual Data. In Computer-Aided Qualitative Data Analysis: Theory, Methods and Practice; Kelle, U., Ed.; Sage: London, UK, 1995.

58. Morse, J.M. Critical Analysis of Strategies for Determining Rigor in Qualitative Inquiry. Qual. Health Res. 2015, 25, 1212-1222. [CrossRef]

59. Eisenhardt, K.M. Building theories from case study research. Acad. Manag. Rev. 1989, 14, 532-550. [CrossRef]

60. Noor, K.B.M. Case Study: A Strategic Research Methodology. Am. J. Appl. Sci. 2008, 5, 1602-1604. [CrossRef]

61. Jick, T.D. Mixing Qualitative and Quantitative Methods: Triangulation in Action. Adm. Sci. Q. 1979, $24,602$. [CrossRef]

Publisher's Note: MDPI stays neutral with regard to jurisdictional claims in published maps and institutional affiliations. 